\title{
Estudo sobre doadores inaptos com suspeita de Hepatite B identificados em Hemocentros
}

\author{
Study on inhibited donors with suspected hepatitis B identified in Blood centers \\ Estudio sobre donantes inaptos con sospecha de hepatitis B identificados en Hemocentros
}

Clícia do Socorro Oliveira Brabo ${ }^{1}$, Maiko Breno Pinheiro dos Santos ${ }^{1}$, Jefison da Silva Lopes ${ }^{1 *}$, Sabrina Macambira Guerra da Rocha ${ }^{1}$, Érika de Oliveira Santos ${ }^{1}$, Maitê dos Santos Feitosa ${ }^{1}$, Amanda Soares Peixoto ${ }^{1}$, Paula Carolina Brabo Monte ${ }^{1}$, Paula Renata Caluff Tozzatti².

\section{RESUMO}

Objetivo: Conhecer a real situação sorológica dos doadores considerados inaptos por infecção pelo HBV em hemocentros de Belém no período de janeiro de 2011 a dezembro de 2015 e estabelecer proporções de positividade através da retestagem. Métodos: Trata-se de um estudo transversal (descritivo e analítico) desenvolvido a partir da coleta de prontuários de doadores de sangue atendidos no período de janeiro de 2011 a dezembro de 2015 no ambulatório de hepatites do Núcleo de Medicina Tropical. Resultados: Do total de 1932 prontuários analisados, 1217 doadores considerados inaptos realizaram a retestagem sorológica no Núcleo de Medicina Tropical. A retestagem mostrou 556 casos $(76,1 \%)$ reagentes para Anti-HBc total, dos quais $408(55,8 \%)$ apresentaram imunidade por contato prévio; 71 (9,7\%) foram reagentes para HBsAg e $454(63,3 \%)$ reagente para Anti-HBs. Não houve diferença significativa para HBsAg positivos quanto à média de idade $(p=0,0642)$ e quanto ao gênero $(p=0,2108)$. Conclusão: $A$ alta infectividade do vírus e os casos positivos para a doença ainda configuram um grave problema de saúde pública por se tratar de uma doença silenciosa. Ressalta-se a importância dos serviços de assistência complementar referenciada para garantir o apoio aos doa dores considerados inaptos pelos hemocentros, uma vez que após o descarte é comum os pacientes encontrarem dificuldade de atendimento no Sistema Único de Saúde.

Palavras chaves: Hepatite, Sorologia, Doadores.

\begin{abstract}
Objective:To Verify the real sorological situation of the blood donors considered unfit because of HBV infection in Belém do Pará Blood centers in the period of january of 2011 to december of 2015 and establish proportions of positivity through re-testing. Methods: his is a cross-sectional study (descriptive and analytical) developed from the collection of medical records of blood donors treated from January 2011 to December 2015 in the hepatitis clinic of Núcleo de Medicina Tropical. Results: Of the total of 1932 records analyzed, 1217 donors considered unfit had the serological retestation in Núcleo de Medicina Tropical. Retention showed 556 cases (76.1\%) total Anti-HBc reagents, of which 408 (55.8\%) had previous contact immunity; $71(9.7 \%)$ were reagents for $\mathrm{HBsAg}$ and $454(63.3 \%)$ reagent for Anti-HBs. There was no significant difference in $\mathrm{HBsAg}$ positive for mean age $(p=0.0642)$ and for gender $(p=0.2108)$. Conclusion: The high infectivity of the virus and the positive cases for the disease still constitute a serious public health problem because it is a silent disease. It is important to highlight the importance of the complementary care services referenced to guarantee support to donors considered unfit by the hemocentres, since after the discard it is common for patients to find difficulty in care in the Brazilian health system.
\end{abstract}

Key words: Hepatitis, Serology, Donors.

\footnotetext{
${ }^{1}$ Unidade de Pronto Atendimento de Icoaraci, Belém do Pará. * E-mail: jefisom@yahoo.com.br

2 Professora da Faculdadade de Medicina da Universidade Federal do Pará.
} 


\section{RESUMEN}

Objetivo: Conocer la real situación serológica de los donantes considerados inaptos por infección por el HBV en hemocentros de Belén en el período de enero de 2011 a diciembre de 2015 y establecer proporciones de positividad a través de la reticencia. Métodos: Se trata de un estudio transversal (descriptivo y analítico) desarrollado a partir de la recolección de prontuarios de donantes de sangre atendidos en el período de enero de 2011 a diciembre de 2015 en el ambulatorio de hepatitis del Núcleo de Medicina Tropical. Resultados: Del total de 1932 prontuarios analizados, 1217 donantes considerados inaptos realizaron la retestación serológica en el Núcleo de Medicina Tropical. La retracción mostró 556 casos (76,1\%) reactivos para AntiHBc total, de los cuales 408 (55,8\%) presentaron inmunidad por contacto previo; 71 (9,7\%) fueron reactivos para HBsAg y $454(63,3 \%)$ reactivo para Anti-HBs. No hubo diferencia significativa para HBsAg positivos en cuanto a la media de edad ( $p=0,0642)$ y en cuanto al género $(p=0,2108)$ Conclusión: La alta infectividad del virus y los casos positivos para la enfermedad todavía configuran un grave problema de salud pública por tratarse de una enfermedad silenciosa. Se resalta la importancia de los servicios de asistencia complementaria referenciada para garantizar el apoyo a los dolores considerados inaptos por los hemocentros, una vez que tras el descarte es común que los pacientes encuentren dificultad de atención en el Sistema Único de Salud.

Palabras claves: Hepatitis, Sorología, Donantes.

\section{INTRODUÇÃO}

A hepatite viral B constitui a causa mais frequente de hepatite crônica, cirrose e carcinoma hepatocelular. Apresenta amplo espectro clínico, desde infecções assintomáticas, oligossintomáticas, até formas fulminantes. A infectividade do vírus da hepatite B (HBV) é de 50 a 100 vezes maior do que a do vírus da imunodeficiência humana (HIV), e a susceptibilidade à infecção é universal (TAUIL et al., 2012).

A infecção pelo vírus da hepatite B (HBV) é um fenômeno global, com aproximadamente 360 milhões de portadores crônicos. Mais de um milhão de indivíduos infectados morrem todo ano devido a complicações da hepatite (VIEIRA et al., 2015).

No Brasil, a doença é considerada um importante problema de saúde pública. Em 2010 foram notificados no Sistema de Informação de Agravos de Notificação (SINAN) 1753 casos de hepatite B na Região Norte, $13,3 \%$ do total no território brasileiro para esse ano, a maioria dos quais nos estados do Amazonas (29,3\%), Acre (23,8\%), Rondônia (19,7\%) e Pará (14,1\%) (BRASIL, 2012).

O primeiro relato de hepatite seguido de transfusão sanguínea ocorreu em 1943, mas somente em 1965 o antígeno Austrália foi relacionado à hepatite pós-transfusional em receptores de sangue. Em 1971, foi introduzido um teste de detecção do antígeno de superfície da hepatite $B$ (HBsAg) para o rastreio de doadores de sangue e, após 1986, foram incluídos em vários países testes de alanina aminotransferase (ALT) e de antígeno de núcleo do vírus B (anti-HBc) na rotina sorológica dos doadores (BEESON, 1943; GOCKE et al., 1969; HOOFNAGLE, 1990; NATIONAL INSTITUTE OF HEALTH, 1995 apud SILVEIRA et al., 2011).

A doação de sangue no Brasil é atualmente regulamentada pelo Ministério da Saúde e pela Agência de Vigilância Sanitária (ANVISA) obedecendo a Resolução no 57 do Diretório Colegiado publicado em 16 de dezembro de 2010 e pelo Decreto 1353 do Ministério da Saúde de 13 de junho de 2011, os quais padronizaram as normas técnicas para procedimentos em hemocentros. Estas regulamentações apoiam as atividades de centros de hemoterapia no Brasil de acordo com os princípios e diretrizes da política brasileira para a transfusão de sangue, componentes e compostos derivados do sangue(BRASIL, 2011).

Apesar da implantação de regulamentações técnicas quanto aos procedimentos hemoterápicos, observase que testes sorológicos positivos para os vírus da hepatite $B$ nos bancos de sangue são importante causa de descarte de bolsas de sangue (SILVEIRA et al., 2011). Os Países que introduziram medidas de rastreio sofreram uma drástica redução nos casos de infecção por hepatite $B$ pós-transfusão. Porém, a transmissão de HBV continua sendo a causa mais comum de infecção adquirida por transfusão (ANJOS et at., 2010). 
As taxas de infecção por hepatite $B$ entre os doadores de sangue é geralmente subestimada em relação ao público em geral e tal situação deve ser analisada de forma cautelosa. Anjos et al (2010) constatou nos exames de triagem que o HBV foi a infecção 3,2 vezes mais prevalente no grupo de doadores inaptos $(11,6$ $\%)$ em relação aos doadores aptos $(3,6 \%)(p<0,001)$.

A realização deste estudo justifica-se devido à importância da realização da retestagem sorológica em doadores considerados inaptos pelos hemocentros de Belém, pois através dos retestes poder-se-á ratificar ou não a infecção pelo HBV; além de poder revelar quantos doadores inaptos estavam imunizados pós exposição ao vírus B e quantos apresentavam achados sorológicos insuficiente para descarte de doação. Conhecer a real situação sorológica dos doadores considerados inaptos por infecção pelo HBV em hemocentros de Belém no período de janeiro de 2011 a dezembro de 2015 e estabelecer proporções de positividade através da retestagem.

\section{MÉTODOS}

Trata-se de um estudo transversal (descritivo e analítico) desenvolvido a partir da coleta de prontuários de doadores de sangue atendidos no período de janeiro de 2011 a dezembro de 2015 no ambulatório de hepatites do Núcleo de Medicina Tropical (NMT). Foram analisados 1932 prontuários de doadores encaminhados ao NMT pelos hemocentros situados na Região Metropolitana de Belém com resultados de sorologias para anti-HBc total reagente ou inconclusiva e HBsAg reagente, inconclusivo ou não reagente.

Os pacientes incluídos neste estudo apresentaram soropositividade para o anti-HBc total ou para HBsAg. A amostra consistiu de 1217 prontuários de doadores, selecionados de modo não probabilístico (amostra por conveniência). Foram excluídos todos aqueles que apresentaram resultados compatíveis com coinfecção por quaisquer outras hepatites virais (HAV, HCV, HDV, HEV).Neste estudo foram coletados dos prontuários dos pacientes atendidos no Núcleo de Medicina Tropical dados referentes à idade, gênero e origem.

\section{Métodos laboratoriais}

Foi coletado de cada participante aproximadamente $20 \mathrm{~mL}$ de sangue periférico através de punção venosa. Todo o procedimento da coleta foi realizado por um profissional habilitado, sendo empregados recursos necessários para a Biossegurança como o uso de luvas e materiais estéril descartáveis para a coleta, assim como, álcool $70 \%$ para a assepsia do local da punção. O material descartado resultante desta coleta sanguínea foi recolhido pelo profissional responsável e encaminhado para o descarte final recomendado para lixo biológico.

\section{Diagnóstico sorológico do hbv}

Em todas as amostras foram realizados testes imunoenzimáticos, sendo testados marcadores HBV específicos (HBsAg- antígeno de superfície do virus da hepatite B, HBcAg- antígeno do córe do vírus $\mathrm{B}$, anti$\mathrm{HBc}$ total- anticorpo total para o núcleo do vírus da hepatite $\mathrm{B}$, e anti-HBs- anticorpo contra o antígeno de superfície do vírus da Hepatite B). Para pesquisa dos marcadores sorológicos do HBV foram utilizados os kits: para a determinação dos antígenos HBsAg o kit ETI-MAK-4 (Diaosrin, Itália), dos anticorpos anti-HBs, o kit ETI-AB-AUK-3 (Diasorin, Itália) e o Anti-HBc total o kit ETI-AB-COREK-PLUS (Diasorin, Itália).

Esses testes possuem caráter qualitativo classificando os indivíduos como reagentes ou não reagentes, e foram realizados de acordo com as instruções de uso recomendadas pelo fabricante do kit a ser utilizado.

Para todos os kits utilizados, as tiras (poços) necessárias para as reações foram retiradas da geladeira com antecedência de uma hora e deixadas à temperatura ambiente, e os reagentes homogeneizados rapidamente no vórtex.

\section{Definições das variáveis empregadas}

Para melhor compreensão dos resultados encontrados neste estudo, serão considerados as seguintes definições apresentadas na tabela 1. 
Tabela 1 - Classificação dos casos e seus critérios sorológicos

\begin{tabular}{ll}
\hline \multicolumn{1}{c}{ Classificação } & \multicolumn{1}{c}{ Criterio sorológico } \\
\hline Teste & Resultado da triagem sorológica realizada no hemocentro. \\
Reteste & Resultado dos marcadores sorológicos realizados no núcleo de medicina tropical \\
Imune por contato prévio & Resultado de anti-HBc total reagente, HBsAg não reagente e anti-HBs reagente no reteste. \\
Restestagem negativa & Resultado de anti-HBc total reagente, HBsAg não reagente e anti-HBs reagente no reteste. \\
Caso confirmado & Anti-HBc total reagente, HBsAg reagente e anti-HBs não reagente no resteste. \\
Imune sem contato prévio & Anti-HBc total não reagente, HBsAg não reagente e anti-HBs reagente.
\end{tabular}

Fonte: Núcleo de Medicina Tropical, 2016.

\section{Análise estatística}

As variáveis qualitativas foram analisadas pelo método qui-quadrado e as quantitativas pelo teste de Mann Whitney. Os softwares Access 2010 e excel 2010 foram utilizados para a organização dos dados e Bioestat 5.3 para as análises estatísticas. O nível de significância alfa $\leq 5 \%$ foi considerado em todas as análises.

Este estudo foi previamente submetido à análise do Comitê de Ética em Pesquisa do Núcleo de Medicina Tropical/Universidade Federal do Pará, seguindo as normas de regulamentação 466/12 do Conselho Nacional de Saúde (CONEP), estando aprovado sob o referido comitê, tendo o parecer de aprovação registado sob o número 1.991.093. Os dados analisados nessa pesquisa provieram de dados secundário (analise prontuários), sob condições de sigilo e anonimato, sem contato direto com paciente dessa forma foi dispensado termo de consentimento livre esclarecido.

\section{RESULTADOS}

Dos 1932 prontuários analisados, 1217 apresentaram critérios de inclusão para compor este estudo. Dentre os doadores atendidos no Núcleo de Medicina Tropical, com suspeição sorológica em testes iniciais, 856 eram do gênero masculino (70,3\%) e 361 do gênero feminino (29,7\%). A média de idade foi de 39 anos, com idade mínima 18 e a máxima 69, apresentando desvio padrão de 11,4.

Os testes iniciais revelaram 986 casos $(81,0 \%)$ com resultado reagente para Anti-HBc total, 227 casos $(18,7 \%)$ inconclusivos e 4 casos $(0,3 \%)$ não reagentes. A presença do antígeno de superfície do vírus $B$ foi constatada em 99 casos $(8,1 \%)$, em 1109 casos $(91,1 \%)$ o resultado foi não reagente e em 9 casos $(0,8 \%) \circ$ resultado foi inconclusivo (Tabela 2 ).

Tabela 2 - Distribuição dos resultados dos testes iniciais

\begin{tabular}{ccccc}
\hline Exame & Resultado & Casos & $\%$ & Total \\
\hline \multirow{3}{*}{ Anti-HBc Total } & Reagente & 986 & 81,0 & \\
& inconclusivo & 227 & 18,7 & 1217 \\
& não reagente & 4 & 0,3 & \\
\hline \multirow{2}{*}{ HBsAg } & não reagente & 1109 & 91,1 & \\
& Reagente & 99 & 8,1 & 1217 \\
& inconclusivo & 9 & 0,8 & \\
\hline
\end{tabular}

Fonte: Núcleo de Medicina Tropical, 2016. 
Do total de 1217 doadores considerados inaptos pelos hemocentros de Belém que compareceram para consulta no ambulatório de hepatites virais no NMT, 731 (60\%) retornaram para a realização do reteste e 486 (40\%) não retornaram.

Dentre os 731 pacientes que retornaram para realizar o reteste, a infecção foi confirmada (anti-HBc total reagente) em 559 retestagens sorológicas $(76,5 \%)$ e 172 retestagens $(23,5 \%)$ mostraram que não houve 0 contato prévio com o vírus $\mathrm{B}$.

O reteste dos 731 pacientes revelou que $496(67,9 \%)$ eram do gênero masculino e $235(32,1 \%)$ do feminino, com média de idade similar a descrita no total de investigados. A retestagem mostrou 556 casos (76,1\%) reagentes para Anti-HBc total; 660 casos (90,3\%) com HBsAg não reagente e 454 casos (63,3\%) com Anti-HBs reagente, como pode ser observado na tabela 3.

Tabela 3: Distribuição dos resultados da retestagem sorológica realizada no NMT

\begin{tabular}{ccccc}
\hline Exame & Resultado & Casos & $\%$ & Total \\
\hline \multirow{2}{*}{ Anti-HBc Total } & Reagente & 556 & 76,1 & \\
& não reagente & 172 & 23,5 & 731 \\
& Inconclusivo & 3 & 0,4 & \\
\hline \multirow{2}{*}{ HBsAg } & não reagente & 660 & 90,3 & \multirow{2}{*}{731} \\
& Reagente & 71 & 9,7 & \\
\hline \multirow{2}{*}{ Anti-HBs } & Reagente & 454 & 63,3 & \multirow{2}{*}{717} \\
& não reagente & 263 & 36,7 & \\
\hline
\end{tabular}

Fonte: Núcleo de Medicina Tropical, 2016.

Em $567(77,6 \%)$ retestes foi confirmada a infecção pelo vírus B (Anti-HBc total reagente). Destes, 408 casos $(55,8 \%)$ adquiriram imunidade após o contato com o HBV (Anti-HBs reagente), 88 casos (12,1\%) tiveram contato prévio, mas não desenvolveram imunidade (Anti-HBc reagente e Anti-HBs não reagente), 71 $(9,7 \%)$ mantiveram a infecção ativa pelo vírus (HBsAg reagente) e 44 casos $(6,0 \%)$ não tiveram contato prévio, porém apresentaram imunidade por vacinação prévia (Anti-HBc total não reagente e Anti-HBs reagente). Em 120 retestes (16,4\%) não foi confirmada a infecção, ou seja, todos os exames sorológicos foram negativos (Gráfico 1).

Gráfico 1 - Representação gráfica da definição dos casos após retestagem sorológica

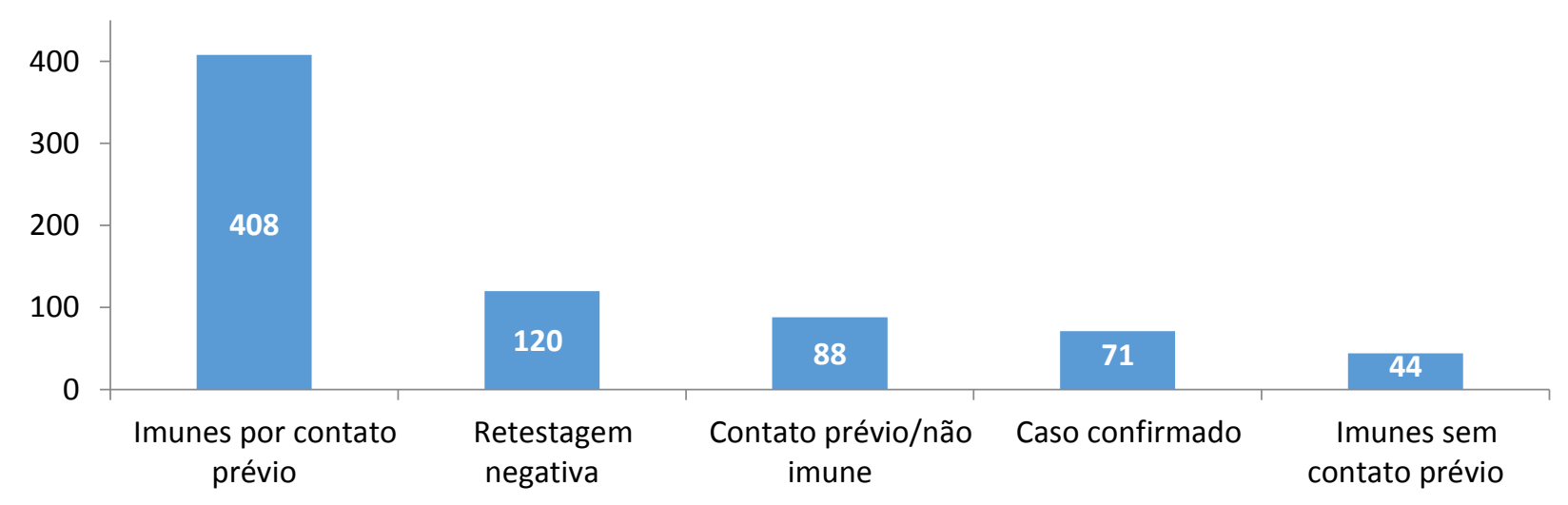

Fonte: Núcleo de Medicina Tropical, 2016. 
Houve uma significativa predominância da positividade na retestagem do anti-HBc confirmando as infecções (559/731) sobre a positividade do HBsAg, confirmando casos ativos do HBV $(71 / 731)(p<0,0001)$.

Constatou-se também um predomínio dos casos com infecção prévia que desenvolveram imunidade, 408/559 (anti-HBs reagente/anti-HBc reagente) sobre os que mantiveram a atividade viral, 71/559 (HBsAg reagente/anti-HBc reagente) ( $p<0,0001$ ), assim como sobre os não imunes após contato com o HBV, 88/559 (anti-HBs não reagente/ Anti-HBc reagente) ( $p<0,0001)$.

A retestagem positiva de anti-HBc no gênero feminino apresentou uma taxa de 81,2\% (191/235) superior $(p=0,0350)$ ao gênero masculino cuja taxa foi de $74,3 \%(368 / 496)$. As taxas de positividade para o $\mathrm{HBsAg}$ não foram diferentes entre os gêneros $(p=0,2108)$, sendo $8,9 \%(21 / 235)$ foram femininos e $10,1 \%(50 / 496)$ masculinos. Não houve diferença significativa entre as médias de idade nos casos $\mathrm{HBsAg}$ reagentes e $\mathrm{HBsAg}$ não reagentes $(p=0,0642)$. A média $(40,26)$ de idade dos casos anti-HBc reagentes (mediana $=40,0)$ foi superior à média dos anti-HBc não reagentes $(37,54$; mediana $=35,0)$, com diferença significativa $(p=0,002)$ (Gráfico 2).

Em relação à origem dos pacientes, verificou-se que $793(65,1 \%)$ eram de Belém, $260(21,3 \%)$ de Ananindeua e 164 (13,5\%) de outros municípios do Pará.

Grafico 2 - Representação gráfica da diferença entre as médias de idade dos casos anti-HBc positivos e anti-HBc negativos.

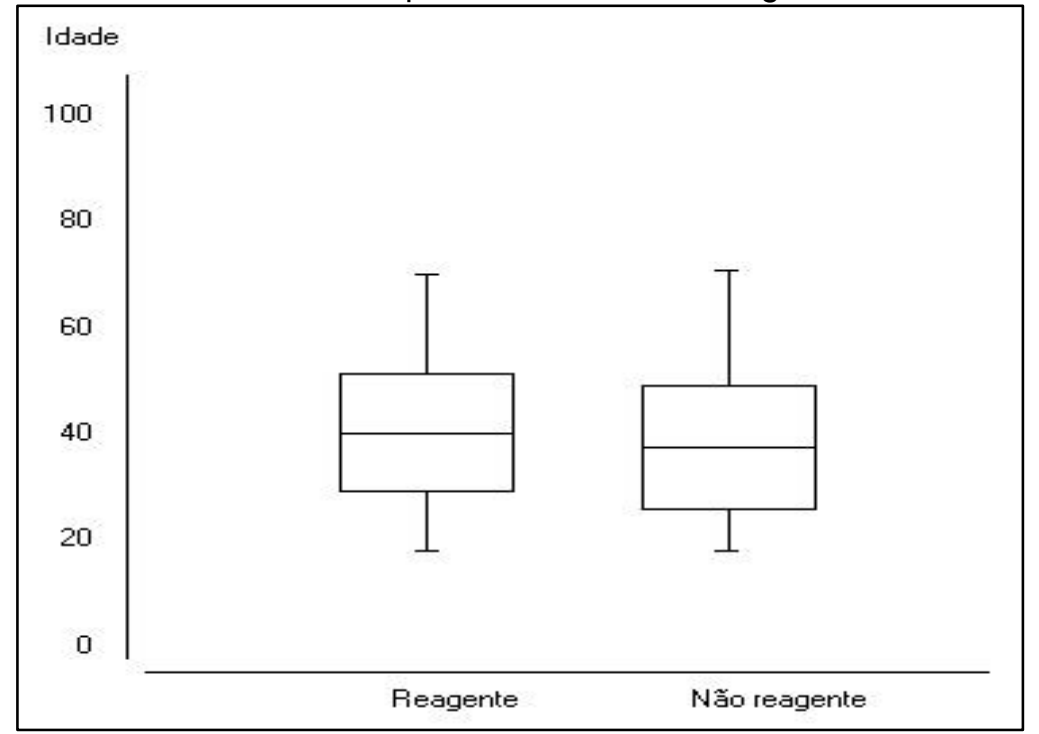

Fonte: Núcleo de Medicina Tropical, 2016.

\section{DISCUSSÃO}

O emprego de testes laboratoriais de triagem considerados de última geração e de alta sensibilidade utilizados pelos bancos de sangue tornou mais efetiva a detecção do vírus da hepatite $B$ diminuindo consideravelmente o número de hepatites pós transfusional. Houve também significativa redução de novos casos da doença a partir da vacinação contra a hepatite $B$ na população em geral, muito embora o risco de infecção continue existindo (FERREIRA et al.,2004; MIRANDA et al., 2000 apud SBEGHEN, 2010).

Os testes de triagem sorológica realizados nos hemocentros não confirmam a positividade para a hepatite B, pois aos serviços de hemoterapia é facultado a realização de testes confirmatórios ou complementares, e, nos casos em que eles não são realizados, os doadores positivos deverão ser encaminhados a serviços especializados de acompanhamento (VALENTE E COLS, 2005). 
A determinação do Anti-HBc total (anticorpo total para o núcleo do vírus da hepatite B) é muito importante devido seu potencial de indicar contato prévio com o HBV( vírus da Hepatite B), mesmo durante a "janela negativa" deste vírus, e associado a dosagem dos outros marcadores virais auxilia também no acompanhamento de pacientes infectados pelo vírus da Hepatite $B$ (HBV) bem como o diagnostico diferencial de hepatites virais. (SBEGHEN e PARABONI, 2010).

Das 731 amostras retestadas no Núcleo de Medicina Tropical o contato prévio com vírus foi confirmado em 559 (76,5\%) amostras (556 amostras com anti-HBc total reagente e 3 amostras com anti-HBc inconclusivo. A infecção foi confirmada em 71 (9,7\%) amostras cujos retestes foram reagentes para o HBsAg (antígeno de superfície do virus da hepatite B), A presença desses marcadores sorológicos ratifica que esses doadores estão inaptos à doação conforme a Portaria № 158, de 04 de fevereiro de 2016, do Ministério da Saúde (BRASIL,2016)

Resultados similares quanto a alta prevalência do vírus B foram encontrados por Borelli et al (2012), ao estudar a taxa de descarte e a prevalência de doenças infecciosas e contagiosas em doadores de sangue em cidades do estado do Paraná. A partir de 278 amostras positivas para doenças infecciosas na triagem sorológica, o autor descartou 156 amostras de doadores, das quais $146(52,5 \%)$ foram positivas para o anti$\mathrm{HBc}$ e 10 (3,6\%) positivas para HBsAg.

Muselmani et al (2014) mostrou, em estudo realizado na Síria composto por 3896 doadores de sangue, $402(10,32 \%)$ amostras reagentes para anti-HBc, porém não reagentes para HBsAg, o que demonstra a alta prevalência do anticorpo no perfil sorológico nesta população de doadores. Ainda neste mesmo estudo, 0 autor enfatiza a enorme variação mundial quanto à prevalência do anti-HBc em países como Egito (10,3\%), Líbano (11\%), Alemanha (1,4\%) e Arábia Saudita (20,8\%), que mostra diferenças na endemicidade do HBV.

Shastry e Bhat (2011) ressaltam a importância de se utilizar o anti-HBc como teste de triagem em doadores de sague. Segundo este autor, a presença deste anticorpo poder auxiliar na prevenção quanto à transmissão de hepatite B oculta pós-transfusional, condição esta em que é possível a detecção do DNA viral sem ocorrer a positividade para o $\mathrm{HBsAg}$, porém o teste para anti-HBc é reagente.

Inicialmente, os resultados obtidos no teste mostraram $99(8,1 \%)$ doadores com positividade para o $\mathrm{HBsAg}$ e $9(0,8 \%)$ doadores com teste inconclusivo para o mesmo marcador. Após a retestagem sorológica, foi constatado que dos 108 doadores com suspeição para a presença do antígeno de superfície no teste, 17 doadores apresentaram soroconversão, 10 doadores não retornaram para a realização do reteste no Núcleo de Medicina Tropical, e os 10 restantes apresentaram retestagem negativa. A presença de casos de positividade para o HBsAg no reteste $(71 / 731)$ foi significativa $(p<0,0001)$ neste estudo, não havendo prevalência quanto ao gênero, uma vez que 8,9 \% (21/235) eram mulheres e 10,1 \% (50/496) homens.

Silveira et al. (2011) delinearam o perfil clinico e epidemiológico de 641 doadores de sangue com sorologia positiva para hepatites virais no sudeste do Brasil e obteve como resultados que $70(7,8 \%)$ doadores apresentaram sorologia positiva para HBsAg. Este resultado está similar ao encontrado no presente estudo em que a positividade para o HBsAg foi reagente em 71 (9,7\%) amostras de doadores após o reteste. Por outro lado, um estudo conduzido por Anjos et al (2011), envolvendo 984 doadores de sangue do hemocentro de Goiás, mostrou a positividade para o HBsAg em apenas $3(0,3 \%)$ indivíduos, caracterizando que o padrão de infecção no território nacional não é homogêneo.

Apesar do vírus B apresentar alta infectividade, grande parcela dos infectados evolui para cura. Ferreira (2000) evidenciou que a maioria dos indivíduos infectados se concentrava em determinadas áreas geográficas, tais como, o Sudeste Asiático, a África Central e a região Amazônica, onde a prevalência de marcadores sorológicos do vírus B variou de $10 \%$ a $95 \%$, sendo que a infecção aguda pelo HBV evoluiu para a cura em $90 \%$ a $95 \%$ dos casos, e em $5 \%$ a $10 \%$ a evolução foi para o estado de portador.

A retestagem das 567 amostras dos doadores com anti-HBc total reagente neste estudo revelou que 408 $(55,8 \%)$ apresentaram soroconversão para o anti-HBs (imunes por contato prévio com o HBV) e em 44 (6,0 $\%)$ amostras o anti-HBs foi o único marcador sorológico reagente. Anjos et al (2011) evidenciou alta taxa de soroconversão e baixa taxa de vacinação prévia em seu estudo, pois dentre os 984 doadores estudados para 
detecção de agentes infecciosos no hemocentro de Goiás, 68 (6,9\%) amostras positivaram para o anti-HBc total, das quais $41(4,2 \%)$ apresentaram imunidade após contato prévio com o vírus B e apenas $3(0,3 \%)$ apresentaram vacinação prévia o HBV.

Beltrán et al, 2011, ao realizarem o perfil sorológico de uma amostra de 510 doadores de quatro diferentes cidades da Colômbia, evidenciou que $227(36,1 \%)$ entraram em contato com o vírus $\mathrm{B}$ e desenvolveram a soroconversão (anti-HBs reagente), achado este similar ao deste estudo, pois houve predomínio de casos de infecção prévia com evolução para imunidade, 408/559 (anti-HBs reagente/anti-HBc reagente). Ainda com base neste estudo feito na Colômbia, os autores identificaram a infecção ativa (HBsAg reagente) em 8 (1,3\%) doadores e $38(6,1 \%)$ mostraram estado vacinal prévio (anti-HBs reagente/ anti-HBc não reagente).

A imunização contra a hepatite $B$ é o método mais seguro de prevenção da doença. A vacina apresenta uma eficácia de $85 \%$ a $90 \%$ em adultos jovens, A presença do anti-HBs confirma proteção ou cura da doença (MEDEIROS et al., 2015).

Apesar de não existir homogeneidade de prevalência de infecção pelo HBV nas regiões brasileiras, Levi et al (2013) afirma que em meio a tantos problemas de saúde pública, as possíveis razões para altas prevalência e incidência do HBV na população do Brasil estão atribuídas à cobertura insuficiente de imunização em doadores e também devido ao fato do programa brasileiro de imunização ser recente, o que levará anos até que todos os doadores de sangue estejam imunizados.

A exclusão de doadores anti-HBc positivos é assunto muito controverso que gera discussões, devido a existência de resultados falso-positivos que eleva o número de doadores que são descartados pelos hemocentros. Um resultado de importante relevância observado neste estudo pauta-se nas 120 (16,4\%) amostras com retestagens negativas para as três sorologias.

A infecção não confirmada pelo vírus B neste grupo de doadores com reteste negativo para as três sorologias demonstra que tais indivíduos poderiam estar suscetíveis à infecção, uma vez que o reteste para o anti-HBs foi negativo. De acordo com o Sistema de Informação do programa Nacional de Imunizações (SIPNI), Ministério da Saúde, a vacina recombinante para hepatite B deve ser ofertada a grupos vulneráveis não vacinados (anti-HBs negativo) ou sem comprovação de vacinação anterior, a saber: doadores de sangue, comunicantes sexuais de pessoas portadoras de HBV, gestantes, após o primeiro trimestre de gestação, trabalhadores da saúde, bombeiros, policiais militares, civis e rodoviários, caminhoneiros, carcereiros de delegacia e de penitenciarias, coletores de lixo hospitalar e domiciliar, pessoas institucionalizadas, potenciais receptores de múltiplas transfusões de sangue ou politransfundido, profissionais do sexo/prostitutas, usuários de drogas injetáveis, inaláveis e pipadas, portadores de DST(doença sexualmente transmissível) (BRASIL, 2015).

Neste estudo identificou-se que 486 (39,9\%) dos pacientes não retornaram para realizar a retestagem. Este fato pode estar associado ao momento informativo na sala de espera onde os pacientes recebiam esclarecimentos sobre o significado dos marcadores sorológicos, além de outros pontos relevantes como prognóstico da possível infecção, transmissibilidade, tratamento, ressaltando-se também que grande parte dos indivíduos (90-95\%) que entravam em contato com o HBV desenvolviam imunidade e que apenas uma pequena porcentagem apresentaria a doença (5-10\%), conforme é enfatizado no Protocolo Clínico e Diretrizes Terapêuticas para o Tratamento da Hepatite Viral Crônica B e Coinfecções, do Ministério da Saúde (BRASIL, 2016). Outro fator que poderia contribuir para o não retorno destes pacientes seria o local de origem, pois 13,5\% pacientes residiam em outros municípios do Estado do Pará.

Dentre os resultados encontrados no reteste houve $88(12,1 \%)$ casos de contato prévio com o vírus, sem a confirmação de evolução para cura ou doença ativa. Este resultado pode estar associado ao período da janela imunológica. Conforme Manual Técnico para o Diagnóstico das Hepatites Virais (BRASIL,2015) este período é compreendido entre a exposição de um indivíduo suscetível à fonte de infecção e o aparecimento de algum marcador sorológico detectável por testes laboratoriais, e para a hepatite $B$ este período pode variar de 30 a 60 dias, quando o HBsAg se torna o marcador detectável. 


\section{CONCLUSÃO}

Apesar da implementação de programas vacinais contra a hepatite $\mathrm{B}$, a alta infectividade do vírus e os casos positivos para a doença ainda configuram um grave problema de saúde pública por se tratar de uma doença silenciosa. A exclusão de doadores anti-HBc positivos ainda é assunto polêmico e passível de ampla discussão quanto à alta sensibilidade dos testes de triagem realizados em hemocentros. Há a necessidade de se encontrar mecanismos de triagem que possam diminuir o número de resultados falso-positivos, uma vez que tais resultados aumentam o descarte de doadores pelos hemocentros.

Ressalta-se a importância dos serviços de assistência complementar referenciada para garantir o apoio aos doadores considerados inaptos pelos hemocentros, já que após o descarte é comum os pacientes encontrarem dificuldade de atendimento no Sistema Único de Saúde (SUS). Campanhas públicas de vacinação e medidas socioeducativas devem ser fortalecidas de forma incansável para que se possa melhorar a conscientização da população sobre os possíveis agravos da hepatite $\mathrm{B}$, bem como reduzir ao máximo as taxas de infecção pelo vírus.

\section{REFERÊNCIAS}

1. ANJOS GR, MARTINS RMB, CARNEIRO MAS et al..Epidemiology of hepatitis B virus infection in first-time blood donors in the southwestern region of Goiás, central Brazil. Rev Bras Hematol Hemoter [periódico na internet].; 2010;33(1).

2. BELTRÁN M, BERRÍO-PÉREZ M, BERMÚDEZ MI et al. Detección de hepatitis B oculta em donantes de bancos de sangre, Colombia 2008-2009. Biomedica. 2011;31(4):580-9.

3. BORELLI SD, MAZZOLA JC, MATTA AC et al.Blood discard rate and the preva-lence of infectious and contagious diseases in blood do-nors from provincial towns of the state of Paraná, Brazil.Revista Brasileira de Hematologia e Hemoterapia.Maringá p. 395-399. 18 dez. 2012.

4. BRASIL. Ministério da Saúde. Secretaria de Vigilância em Saúde. Departamento de DST, Aids e Hepatites Virais. ABCDE do diagnóstico para as hepatites virais - Brasília, 2009.

5. BRASIL. Ministério da Saúde. Secretaria de Vigilância em Saúde. Departamento de DST, Aids e Hepatites Virais. Boletim Epidemiológico - Hepatites Virais- Brasília, 2015.

6. BRASIL. Ministério da Saúde. Secretaria de Vigilância em Saúde. Departamento de DST, Aids e Hepatites Virais -. Manual Técnico para o Diagnóstico das Hepatites Virais Brasília: Ministério da Saúde, 2015.

7. BRASIL. Ministério da Saúde. Portaria № 1.353, de 13 de Julho de 2011,Regulamento Técnico de Procedimentos hemoterápico, Brasília, 2011.

8. BRASIL. Ministério da Saúde. Portaria № 158, de 04 de fevereiro de 2016, Diário Oficial da União de 05/02/2016 (nº 25, Seção 1, pág. 37), Brasília, 2016.

9. BRASIL. Ministério da Saúde. Secretaria de Vigilância em Saúde, Departamento de DST, Aids e Hepatites Virais,- Protocolo Clínico e Diretrizes Terapêuticas para o Tratamento da Hepatite Viral Crônica B e Coinfecções. Programa Nacional para a Prevenção e o Controle das Hepatites Virais, Brasília, 2016.

10. BRASIL. Ministério da Saúde. www.DATASUS.gov.br; Sistema de Informações do Pragrama Nacional de Imunizações, 2016.

11. FERREIRA MS. Diagnóstico e tratamento da hepatite B. Revista da Sociedade Brasileira de Medicina Tropical : 2000 33(4):389-400.

12. LEVI JE, PEREIRA RAD, POLITE MBC et al.. One window-period donation in two years of individual donor-nucleic acid test screening for hepatitis B, hepatitis C and human immunodeficiency vírus. Rev Bras Hematol Hemoter [periódico na internet].; 2013;35(3):16770.

13. MEDEIROS RH, FIGUEIREDO AEPL, FIGUEIREDO CEP et al.. Low response to intradermal hepatitis $B$ vaccination in incident hemodialysis patients. J Bras Nefrol.;2015, (33):45-9.

14. MUSELMANI W, HABBAL W, MONEM F. Prevalence of "anti-HBc alone" among Syrian blood donors. J Infect Dev Ctries; 2014 , 8(8):1013-1015.

15. SBEGHEN MD, PARABONI MLR. Prevalência da reatividade ao anti-HBc total em candidatos à doação de sangue, submetidos à pré-triagem sorológica pelo vírus da hepatite B no município de Erechim/RS. Perspectiva, Erechim. v.34, n.125, p. 165-172, março/2010.

16. SHASTRY S, BHAT SS. Prevention of post-transfusion hepatitis by screening of antibody to hepatitis B core antigen in healthy blood donors. Mediterr J Hematol Infect Dis. 2011;3(1): 1-5.

17. SILVEIRA L, SCHIAVON LL, SILVA KP et al. Clinical and epidemiological profile of blood donors with positive serology for viral hepatitis in southern Brazil. Rev Soc Bras Med Trop 2011; 44:269-273

18. TAUIL MC, AMORIM TR, PEREIRA GFM et al. Mortalidade por hepatite viral B no Brasil, 2000-2009. Cad. Saúde Pública, Rio de Janeiro [periódico na internet].; 28(3):472-478, mar, 2012.

19. VALENTE VB, COVAS DT, PASSOS ADC. Marcadores sorológicos das hepatites $B$ e $C$ em doadores de sangue do Hemocentro de Ribeirão Preto, SP. Revista da Sociedade Brasileira de Medicina Tropical 38(6): 488-492, Nov-dez, 2005.

20. VIEIRA GD, FLORÃO M, CASTRO KPO et al. Hepatitis B in Rondônia (Western Amazon Region, Brazil): descriptive analysis and spatial distribution. Arq Gastroenterol, v. 52 no. 1 - jan./mar. 2015. 